\title{
Efeitos do laser de diodo de alta potência e da fotobiomodulação em dentes de ratos reimplantados tardiamente
}

\author{
Effects of high power diode laser and photobiomodulation therapy prior \\ delayed replantation in rats
}

\author{
Flávia de Moura PEREIRA ${ }^{a}\left(\right.$ D) , Adriana Aparecida de SOUZA ${ }^{a}$ (i), Erica dos Santos CARVALHO ${ }^{\text {(D) }}$, \\ Isabel MELLO ${ }^{c}$ (i), Denise Pontes RALDI ${ }^{a}$ (B) \\ aUNITAU - Universidade de Taubaté, Departamento de Odontologia, Taubaté, SP, Brasil \\ bUFBA - Universidade Federal da Bahia, Faculdade de Odontologia, Salvador, BA, Brasil \\ 'Dalhousie University, Faculty of Dentistry, Department of Dental Clinical Sciences, Halifax, NS, Canadá
}

\begin{abstract}
Como citar: Pereira FM, Souza AA, Carvalho ES, Mello I, Raldi DP. Efeitos dos laser de diodo de alta potência e da fotobiomodulação em dentes de ratos reimplantados tardiamente. Rev Odontol UNESP. 2019;48:e20180144. https://doi.org/10.1590/1807-2577.14418
\end{abstract}

\begin{abstract}
Resumo
Introdução: A busca por protocolos efetivos para reduzir a incidência de reabsorções radiculares e favorecer a reparação do ligamento periodontal perdido ainda representa um grande desafio, tendo em vista o prognóstico desfavorável dos reimplantes dentais tardios. Objetivo: Avaliar, por meio da análise histológica, os efeitos do laser de alta potência e da fotobiomodulação na ocorrência de reabsorção radicular e no reparo periodontal, em dentes reimplantados tardiamente. Material e método: Foram utilizados 50 incisivos centrais direitos de ratos Wistar. Após a extração, os espécimes foram divididos em cinco grupos $(\mathrm{n}=10)$ : G1 (controle positivo): reimplante imediato; G2 (controle negativo): reimplante tardio (RT): espécimes mantidos em ambiente seco por 60 minutos, sem tratamento adicional; G3: RT associado ao tratamento da superfície radicular com laser diodo de alta potência ( $810 \mathrm{~nm}, 1.5 \mathrm{~W})$; G4: RT + superfícies radiculares e feridas alveolares tratadas com fotobiomodulação (laser diodo $660 \mathrm{~nm}, 30 \mathrm{~mW}$ e $780 \mathrm{~nm}, 40 \mathrm{~mW}$, respectivamente); G5: RT + superfícies radiculares irradiadas com laser de alta e alvéolos com fotobiomodulação, nos mesmos parâmetros que G3 e G4, respectivamente. Após 60 dias, os animais foram eutanasiados. Os espécimes foram processados para análise histológica. Resultado: G3 e G5 apresentaram as menores médias de scores com relação à ocorrência de reabsorções radiculares e anquilose, quando comparados a G2 e G4 (Teste Kruskall-Wallis, p<0,05). Com relação ao reparo periodontal, todos os grupos experimentais (G3, G4 e G5) apresentaram médias de escores inferiores (Teste Kruskall-Wallis, $\mathrm{p}<0,05$ ) comparadas ao G1 e semelhantes ao G2 (Teste Kruskall-Wallis, $p>0,05)$. Conclusão: 0 laser de alta potência, associado ou não à fotobiomodulação, diminuiu a ocorrência das reabsorções radiculares e da anquilose, e a fotobiomodulação não favoreceu o controle das reabsorções radiculares nem o reparo periodontal.
\end{abstract}

Descritores: Avulsão dentária; lasers; reabsorção da raiz; reimplante dentário.

\begin{abstract}
Introduction: The search for effective protocols for a lower incidence of root resorptions reduction and for a favor periodontal repair still represents a great challenge, considering the unfavorable prognostic of the delayed replanted tooth. Objective: To evaluate by histologic analyses the effects of high power diode laser and photobiomodulation on the occurrence of root resorption and on the tissue repair of delayed replanted teeth. Material and method: Fifty right central incisors of Wistar rats were used. After the extraction, the specimens were assigned to 5 groups $(n=10)$ : G1 and G2 were the control groups-with no treatment and they were respectively submitted to immediate and delayed replantation (DR- 60 minutes after the extraction). The other three groups received tissue repair treatment prior the DR: G3 - root surfaces were irradiated with high power laser $(810 \mathrm{~nm}, 1.5 \mathrm{~W})$; G4- root surfaces and the alveolar wounds were irradiated with low power laser (photobiomodulation), respectively with $660 \mathrm{~nm}, 90 \mathrm{~mW}$
\end{abstract}


and $780 \mathrm{~nm}, 40 \mathrm{~mW}$; G5 - root surfaces were irradiated with high power and the alveolar wound received photobiomodulation with the same parameters used in G3 and G4. After 60 days the animals were euthanized. The specimens were processed for histological analyses. Result: The histologic analysis showed lower means values of scores of root reabsorptions and ankylosis in G3 and G5 when compared to G2 and G4 (Kruskall-Wallis test, p>0.05). Regarding the periodontal repair, all the experimental groups (G3, G4 and G5) presented lower means values of scores than G1 (Kruskall-Wallis test, p <0.05) and similar values to G2 (Kruskall-Wallis test, $\mathrm{p}>0.0 .5$ ). Conclusion. High power laser reduced the occurrence of root resorption and photobiomodulation did not enhance the tissue healing process in delayed tooth replantation in rats.

Descriptors: Tooth avulsion; lasers; root resorption; tooth replantation.

\section{INTRODUÇÃO}

As lesões dentárias traumáticas são consideradas atualmente a quinta doença ou injúria mais prevalente no mundo ${ }^{1}$ e representam uma das principais causas de perda dentária e lesão pulpar em adolescentes e crianças $^{2}$. Dentre as lesões traumáticas dentárias, a avulsão representa o trauma mais severo por causar danos tanto à estrutura pulpar quanto à estrutura periodontal, como o rompimento e a necrose do ligamento periodontal. Após 15 minutos expostas ao meio externo, as células do ligamento periodontal tornam-se inviáveis e necrosam, estimulando o início de um processo inflamatório que pode resultar na reabsorção radicular³.

Nos casos de reimplante tardio, além do tratamento endodôntico para eliminar a contaminação microbiana, faz-se necessário um tratamento da superfície radicular visando à remoção do ligamento periodontal necrosado, preservando a estrutura radicular e promovendo uma superfície que possibilite o reparo periodontal ${ }^{4}$. Vários estudos têm sido realizados com o objetivo de prevenir ou estabilizar os processos reabsortivos e de regeneração do ligamento periodontal, por meio do tratamento de superfícies radiculares com substâncias químicas, como fluoreto de sódio acetalozamida ${ }^{4}, 1$ a 2,4\%5, bifosfanatos ${ }^{6}$, dentre outras.

A fotobiomodulação, devido aos seus efeitos bioestimuladores, favorece a cicatrização, agindo como anti-inflamatório e analgésico ${ }^{7,8}$. Esses efeitos estão relacionados aos estímulos de diversos sistemas biológicos, como aumento da produção de ATP, aumento da atividade enzimática e da atividade celular, e aumento do transporte de elétrons ${ }^{9,10}$.

Vilela et al.11 verificaram, em dentes de ratos reimplantados, que, nos grupos em que se utilizou a fotobiomodulação, ocorreu menor quantidade de reabsorções, quando comparados ao grupo controle. Além disso, a análise histológica da polpa dentária revelou que houve menor quantidade de áreas inflamadas e necróticas.

Estudos na área da periodontia têm verificado que a utilização de lasers de alta potência para tratamento de superfícies radiculares comprometidas provoca alterações favoráveis em sua estrutura, assim como a sua descontaminação, favorecendo a adesão de células e a inserção de fibras do ligamento periodontal ${ }^{12,13}$. Da mesma forma, resultados promissores foram observados por Carvalho et al. ${ }^{14}$, com relação ao controle dos processos reabsortivos, após reimplante tardio de dentes de ratos, quando da irradiação de superfícies radiculares com laser diodo de alta potência. Entretanto, os autores não constataram a reinserção favorável do ligamento periodontal na maioria das amostras.

Pelo exposto, a associação de lasers de alta potência e da fotobiomodulação poderia promover resultados favoráveis, tanto no controle das reabsorções como no processo de reparo do ligamento periodontal. Considerando-se essa hipótese, somada ao fato de que até o presente momento não se encontrou um protocolo de tratamento realmente efetivo para estabilização das reabsorções e para o reparo do ligamento periodontal, justifica-se a investigação de novos protocolos que possam melhorar o prognóstico dos dentes reimplantados tardiamente. 


\section{MATERIAL E MÉTODO}

\section{Modelos Experimentais}

Foram utilizados 50 incisivos superiores direitos de ratos machos (Rattus norvegicus albinus) da raça Wistar, com 10 semanas de idade e peso corporal entre 250 e 300 g. Os animais foram fornecidos pelo biotério da Faculdade de Odontologia de São José dos Campos (UNESP) e mantidos no laboratório de Fisiologia da Universidade de Taubaté (UNITAU) em gaiolas identificadas de acordo com o grupo experimental, em temperatura ambiente, alimentados com água e ração ad libitum.

Este estudo foi aprovado pelo Comitê de Ética para Experimentação Animal da UNITAU (CEAU/UNITAU 004/11).

\section{Intervenções Cirúrgicas}

Os animais foram anestesiados, com uma associação de cloridrato de xilazina (AnasedanAgribrands do Brasil Ltda., Paulínia-SP, Brasil) e cloridrato de ketamina base (DopalenaAgribrands do Brasil Ltda., Paulínia-SP, Brasil), na proporção de 0,7 / 0,5 mL e em uma dose de $0,1 \mathrm{~mL}$ por $100 \mathrm{~g}$ de peso ${ }^{14}$. A anestesia, via intraperitoneal, foi administrada com seringas de insulina descartáveis.

Em seguida, foi realizada a antissepsia da porção anterior da maxila com Chlorohex (solução de clorexidina a 2\% - Ceras Johnson Ltda., Jacarepaguá-RJ, Brasil), sindesmotomia, luxação e extração do incisivo superior direito, simulando uma avulsão dentária. Para os procedimentos de sindesmotomia e luxação, foi utilizada uma lâmina de bisturi 11, e para extração dentária, foi utilizado o porta-agulha Mathieu (Wilcos do Brasil Indústria e Comércio Ltda., Petrópolis-RJ, Brasil).

\section{Divisão de Grupos (Preparo dos Dentes e Reimplante)}

O cálculo amostral do presente estudo foi realizado com Programa BioEstat 5.0 (Sociedade Civil de Mamirauá, Belém-PA, Brasil). Os dados utilizados neste cálculo foram embasados em estudos da literatura. Para tanto, valeu-se do teste t para uma amostra, com um power de 0,8 e nível de significância $\alpha=0,05$. 0 resultado do teste sugeriu um $n=10$ amostras para cada grupo. Os espécimes foram divididos em dois grupos controle e três experimentais ( $\mathrm{n}=10)$, de acordo com o tratamento de superfície radicular e o tratamento do alvéolo aplicados, como segue:

- G1 (controle positivo) - após a exodontia, foi realizada a irrigação do alvéolo com soro e, em seguida, os dentes foram reimplantados imediatamente com os remanescentes do ligamento periodontal.

- G2 (controle negativo - reimplante tardio) - os dentes foram mantidos em ambiente seco por 60 minutos e reimplantados após este período, sem tratamento adicional.

- G3 (reimplante tardio + laser de alta potência) - os espécimes receberam tratamento de superfície radicular, de acordo com protocolo testado em estudo anterior ${ }^{14:}$ a superfície radicular foi irradiada com laser de diodo de alta potência (Tera Surgery, protótipo da DMC Equipamentos Ltda., São Carlos-SP, Brasil), com comprimento de onda de $810 \mathrm{~nm}$, no modo contínuo, fibra óptica de quartzo de $600 \mu \mathrm{m}$, feixe de luz guia de diodo vermelho de $650 \mathrm{~nm}$, $1.5 \mathrm{~W}$ de potência input (monitor). A irradiação foi realizada com movimentos de varredura, 
com a fibra óptica posicionada com angulação de $45^{\circ}$ em contato com a superfície radicular, por um tempo de trinta segundos, sendo 10 segundos para as faces proximais e cinco segundos para as faces vestibular e lingual.

- Grupo 4 (reimplante tardio + fotobiomodulação) - os espécimes receberam tratamento do alvéolo dentário e da superfície radicular com fotobiomodulação, respectivamente, nos seguintes parâmetros: Alvéolo - modo pontual, contínuo, contato direto, comprimento de onda de $780 \mathrm{~nm}$, intensidade de $40 \mathrm{~mW}$ por um minuto, totalizando $60 \mathrm{~J} / \mathrm{cm}^{2}$, em toda sua extensão. Superfície radicular - modo pontual e por varredura no sentido longitudinal da raiz, comprimento de onda de $660 \mathrm{~nm}$, intensidade de $30 \mathrm{~mW}$ por três minutos, com um minuto nas superfícies proximais e meio minuto nas superfícies vestibulares e palatinas ${ }^{7,10}$, totalizando $90 \mathrm{~J} / \mathrm{cm}^{2}$.

- Grupo 5 (laser de alta potência + fotobiomodulação) - as superfícies radiculares foram irradiadas com laser de alta potência e os alvéolos foram tratados com fotobiomodulação, nos mesmos parâmetros dos grupos 3 e 4, respectivamente.

Em todos os espécimes dos grupos experimentais, as papilas dentárias foram excisionadas com uma lâmina de bisturi n. ${ }^{-}$11, para a exposição do canal radicular. A polpa foi removida, via retrógrada, com limas Flexofile \#15 (Dentsply-Maillefer Instruments S.A., Ballaigues, Suíça), os canais radiculares foram instrumentados com limas \# 20 e \# $25 \mathrm{~K}$ - Flexofile (Dentsply Maillefer) e copiosamente irrigados com hipoclorito de sódio a $1 \%(\mathrm{NaOCl})$, seguido de irrigação final com 17\% de EDTA-T (Farmácia Fórmula \& Ação, São Paulo, Brasil) por 3 min. Os canais radiculares foram secos com pontas de papel estéreis e preenchidos com pasta de hidróxido de cálcio (Calen; S.S. White Artigos Dentários Ltda., Rio de Janeiro, Brasil).

Em seguida, os alvéolos dos animais foram irrigados com solução fisiológica e, com o auxílio de uma pinça hemostática curva, os dentes foram reimplantados em seus respectivos alvéolos.

Nenhum tipo de contenção foi utilizado e todos os animais receberam dose única de 20.000 U.I. de Penicilina G Benzatina por via intramuscular. Nas primeiras 12 horas pré e pós-operatórias, os animais receberam apenas água e a alimentação se deu por meio de ração moída durante sete dias.

\section{Análise Histológica}

Após o período de sessenta dias, os animais foram anestesiados e eutanasiados por superdose de anestésico. Os lados direito e esquerdo da maxila foram separados na linha mediana, com uma lâmina cirúrgica \#15, e as peças, contendo o dente reimplantado e o seu homólogo, foram fixadas em formol $10 \%$ por sete dias.

As peças foram lavadas por 24 horas em água corrente e desmineralizadas em solução de 100 g EDTA (ácido etilieno diamino tetracético - pH 7), desidratadas e embebidas em blocos de parafina. Foram realizados, por meio de um micrótomo rotativo (modelo 297, ANCAP, São Paulo-SP-Brasil), cortes seriados no sentido longitudinal (vestibulolingual) com $6 \mu \mathrm{m}$ de espessura até que se esgotasse o bloco de parafina. As lâminas foram coradas pela técnica da Hematoxilina e Eosina (H. E). As imagens das seções longitudinais foram capturadas com uma máquina fotográfica digital (Canon Powershot A640 - Newport News, VA, USA) acoplada a um microscópio (Carl Zeiss, Axiolab, Jena, Alemanha). Foram analisadas 10 lâminas por espécime, com magnificações de 50×, 100×, 200× e 400×. 


\section{Análise Descritiva dos Eventos Histológicos}

Para análise descritiva dos eventos histológicos, foram considerados os seguintes parâmentros: características do tecido conjuntivo formado no espaço periodontal, presença de cemento, reinserção e direção de fibras periodontais, presença de reabsorção inflamatória, substitutiva e anquilose. Lacunas de reabsorção na superfície radicular com presença de células inflamatórias na área foram definidas como reabsorção inflamatória; lacunas obliteradas por osso foram definidas como reabsorção substitutiva, e as áreas com ausência do espaço periodontal (contato direto entre a superfície radicular e o tecido ósseo adjacente) foram definidas como anquilose.

\section{Análise dos Eventos Histológicos por Meio de Escores}

Ocorreram reabsorções inflamatórias e substitutivas, e anquilose, que foram analisadas por terços e registradas numa tabela. Foram, então, atribuídos os seguintes escores: Escore 0 = Ausente; Escore 1 = Leve - até um terço (33\%); Escore 2 = Moderada - de um terço a dois terços (33 a 66\%), e Escore 3 = Severa - mais que dois terços ( $>66 \%)$.

Para a análise do processo de reparo periodontal, foram avaliadas as características do tecido conjuntivo formado no espaço periodontal e a reinserção das fibras periodontais à superfície radicular externa. Foram estabelecidos escores de acordo com as características encontradas:

- Características do tecido Conjuntivo: Escore 0 - tecido conjuntivo ausente; Escore 1 -tecido conjuntivo delgado/desorganizado, e Escore 2 - presença de tecido conjuntivo espesso/organizado.

- Reinserção das fibras do ligamento periodontal (LP): Escore 0 - fibras do LP ausentes; Escore 1 - fibras do LP não inseridas ao cemento, e Escore 2 - fibras do LP reinseridas ao cemento.

Todas essas análises foram executadas pelo mesmo examinador devidamente treinado, que desconhecia a qual grupo os cortes histológicos pertenciam.

\section{Análise Estatística}

A análise estatística dos eventos histológicos, por meio de escores, foi realizada com Programa BioEstat 5.0 e com o teste estatístico de Kruskal-Wallis com nível de significância de 5\%. Quando este teste indicou diferença estatisticamente significante, o teste de Dunn foi utilizado para comparações individuais.

\section{RESULTADO}

\section{Resultados da Análise Semiquantitativa dos Eventos Histológicos (scores)}

Os resultados da análise semiquantitativa, por meio de scores, dos eventos histológicos na superfície radicular e no ligamento periodontal estão descritos na Tabela 1. 
Tabela 1. Comparações das médias dos escores dos eventos histológicos na superfície radicular e do processo de reparo periodontal, no período de 60 dias

\begin{tabular}{|c|c|c|c|c|c|}
\hline & \multicolumn{3}{|c|}{ Ocorrência de reabsorção e anquilose } & \multicolumn{2}{|c|}{ Reparo Periodontal } \\
\hline & \multicolumn{3}{|c|}{$\begin{array}{c}\text { 0- ausência, } 1 \text { - até } 1 / 3,2 \text { - de } 1 / 3 \text { a } 2 / 3,3 \text { - mais } \\
\text { que } 2 / 3\end{array}$} & Tecido conjuntivo & Reinserção de fibras \\
\hline & \multirow[t]{3}{*}{$\begin{array}{l}\text { Reabsorção } \\
\text { inflamatória }\end{array}$} & \multirow{3}{*}{$\begin{array}{l}\text { Reabsorção } \\
\text { substitutiva }\end{array}$} & \multirow[t]{3}{*}{ Anquilose } & 0-Ausente & 0-Ausência \\
\hline & & & & 1- Fino/desorganizado & 1- Fibras não aderidas \\
\hline & & & & 2- Denso/organizado & 2- Fibras aderidas \\
\hline G1 & $0.17^{\mathrm{a}}$ & $0,22^{c}$ & $0.35^{f}$ & $1,52^{\mathrm{A}}$ & $1,57^{\mathrm{C}}$ \\
\hline G2 & $1,59 \mathrm{~b}$ & $2,29 d$ & $1,89 \mathrm{~g}$ & $0,65^{\text {B }}$ & $0,68^{\mathrm{D}}$ \\
\hline G3 & $0,38^{a}$ & $0,58^{c}$ & $0.46^{f}$ & $0,90^{\mathrm{B}}$ & $0,85^{\mathrm{D}}$ \\
\hline G4 & $1,42^{b}$ & $1,67 \mathrm{~d}$ & $1,50 \mathrm{~g}$ & $0,82^{\mathrm{B}}$ & $0,82^{\mathrm{D}}$ \\
\hline G5 & $0,32^{\mathrm{a}}$ & $0,66^{c}$ & $0,52^{\mathrm{f}}$ & $0,85^{\mathrm{B}}$ & $0,80^{\mathrm{D}}$ \\
\hline
\end{tabular}

Letras diferentes nas colunas indicam diferença estatisticamente significante (Teste Kruskall-Wallis, $p<0,05$ ).

Os grupos G3 e G5 apresentaram as menores médias de scores com realação à ocorrência de reabsorções radiculares inflamatórias e substitutivas, e anquilose, quando comparados ao G2 e ao G4 $(\mathrm{p}<0,05)$.

Com relação ao reparo periodontal, todos os grupos experimentais (G3, G4 e G5) apresentaram médias de escores inferiores $(p<0,05)$, quando comparados ao G1, e semelhantes ao G2 (p>0.0.5).

\section{Resultados da Análise Descritiva dos Eventos Histológicos}

\section{G1 (Controle Positivo)}

A maioria dos espécimes apresentou a superfície radicular com ausência de reabsorção inflamatória e substitutiva, e anquilose. Quando presentes, as reabsorções foram constatadas apenas em poucos pontos e em menos de um terço da raiz (leve). Observou-se um tecido conjuntivo espesso e organizado, e inserção das fibras do ligamento periodontal em sete espécimes (Figuras 1A e 1B).
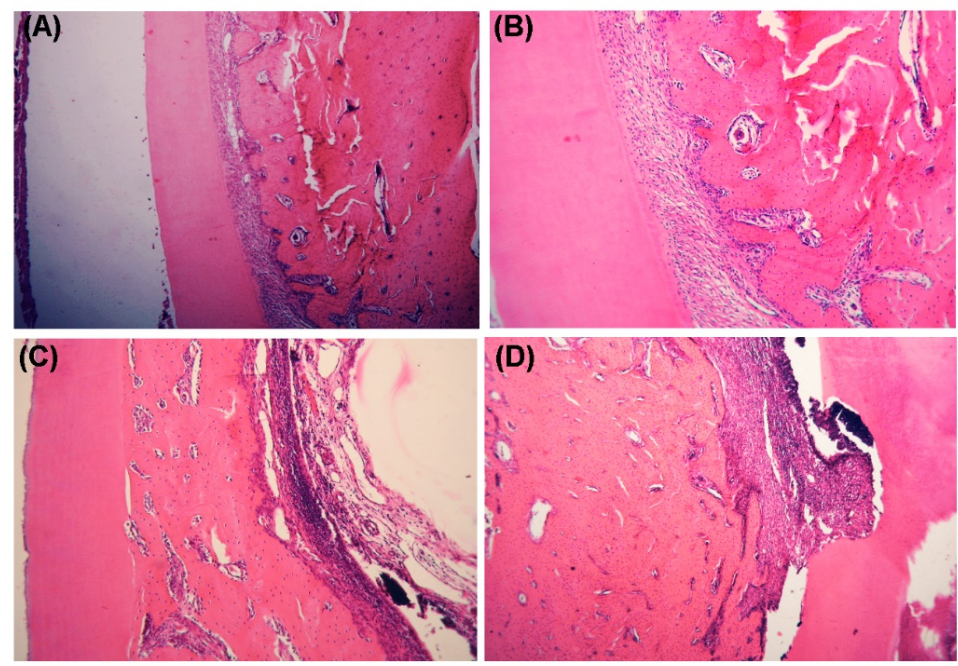

Figura 1. Cortes histológicos representativos dos grupos controle: G1 (controle positivo) - (A) e (B) Ausência de reabsorção inflamatória e substitutiva, e anquilose, e reinserção das fibras do ligamento periodontal (Aumentos de 50× e 100×, respectivamente). G2 (controle negativo) - (C) Áreas extensas de reabsorção substitutiva e, em vários pontos, contato direto com o tecido ósseo (anquilose) Aumento 50x;

(D) Áreas extensas de reabsorção inflamatória e ausência de fibras do ligamento periodontal (100×). 


\section{G2 (Controle Negativo)}

Em quase todos os espécimes, foram observadas reabsorções no cemento e na dentina em mais de um terço da raiz (moderada ou intensa), nas quais verificaram-se células inflamatórias ou substituídas por tecido ósseo e, em muitos pontos, contato direto da superfície radicular com o tecido ósseo adjacente - anquilose (Figura 1C). 0 tecido conjuntivo apresentou-se desorganizado e afastado, e as fibras do ligamento periodontal, finas e dispersas, sem reinserção à superfície radicular (Figuras 1C e 1D).

\section{G3 (Laser de Alta Potência - Superfície Radicular)}

Neste grupo, a maioria dos espécimes apresentou ausência ou pequenos pontos (grau leve) de reabsorções radiculares, tanto inflamatória como substitutiva. A ocorrência de anquilose foi pequena ou ausente. Entretanto, diferentemente do grupo controle positivo, o tecido conjuntivo adjacente apresentou-se, na maioria dos espécimes, delgado e desorganizado, e, apenas em um espécime deste grupo, houve reinserção das fibras periodontais em alguns pontos da superfície radicular (Figuras 2A e 2B).
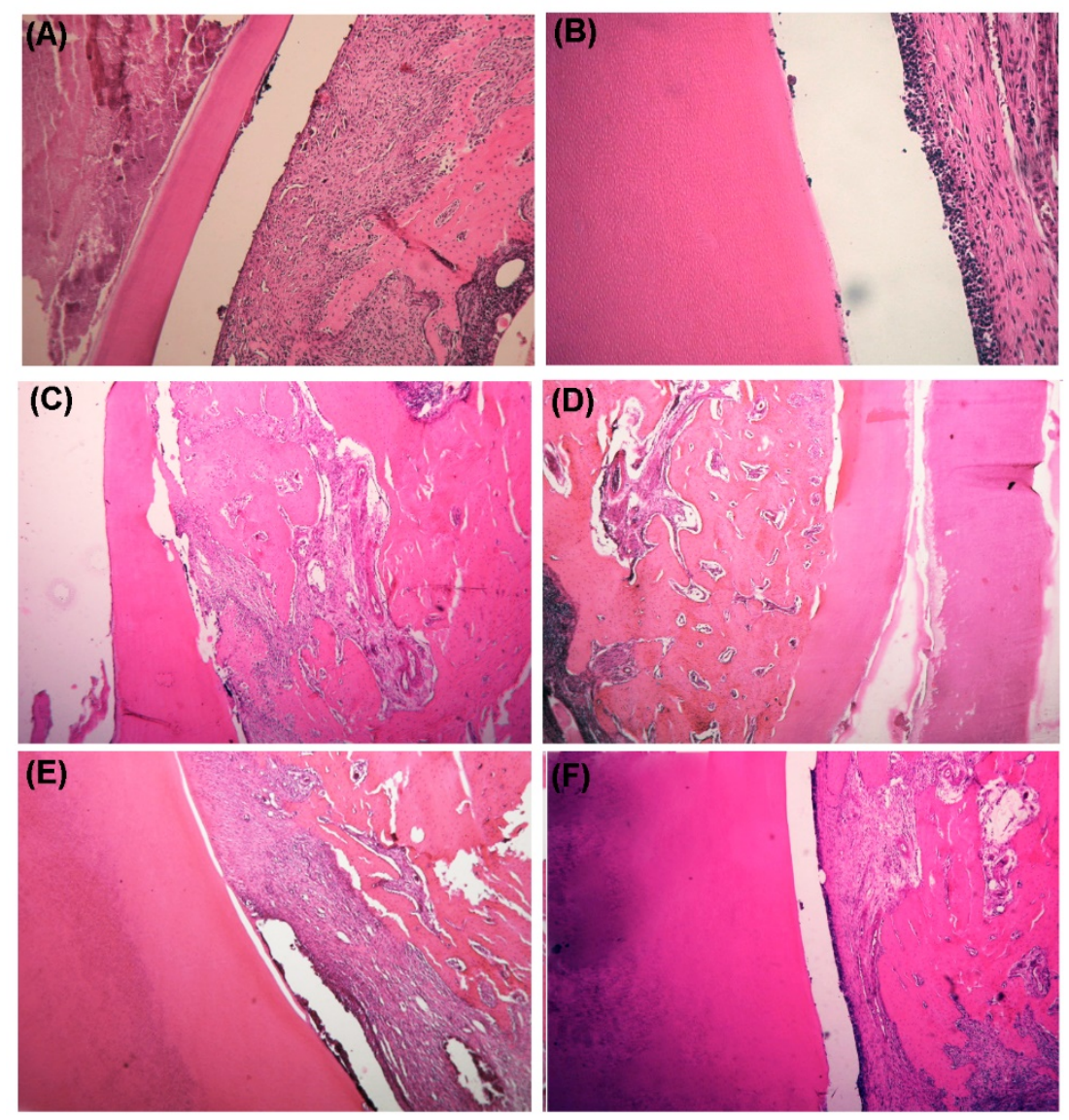

Figura 2. Cortes histológicos representativos dos grupos experimentais. G3: (A) e (B) - Ausência de reabsorção inflamatória e substitutiva, e anquilose. Tecido conjuntivo espesso e organizado, porém com

fibras do ligamento periodontal afastadas da superfície radicular (50× e 200×). G4: (C) - Áreas de reabsorção da superfície radicular com presença de células inflamatórias (50x) e (D) Áreas extensas de reabsorção substitutiva e anquilose $(50 \times)$. G5: (E) - Ausência de reabsorção radicular e anquilose. Tecido conjuntivo organizado e com inserção das fibras do ligamento periodontal em alguns pontos (50x); (D) -

Ausência de reabsorção radicular e ligamento periodontal desorganizado (50x) e (F) - Ausência de inserção de fibras do ligamento periodontal. 


\section{G4 (Fotobiomodulação)}

Em quase todos os espécimes, o cemento e a dentina encontraram-se reabsorvidos, com presença de células inflamatórias, ou substituídos por tecido ósseo, com a superfície radicular apresentando contato com o tecido ósseo adjacente (anquilose) (Figura 2D). Da mesma forma que no G3, o tecido conjuntivo adjacente apresentou-se delgado e desorganizado, e, apenas em um espécime deste grupo, houve reinserção das fibras periodontais em alguns pontos da superfície radicular (Figura 2C).

\section{G5 (Laser de Alta Potência + Fotobiomodulação)}

Neste grupo, a maioria dos espécimes apresentou ausência ou pequenos pontos de reabsorção inflamatória ou substitutiva (leve). Em alguns espécimes, foram observados pontos de contato direto com o osso (anquilose). 0 tecido conjuntivo adjacente apresentou-se delgado e desorganizado, e, apenas em dois espécimes deste grupo, houve reinserção das fibras periodontais em alguns pontos da superfície radicular (Figuras 2E e 2F).

\section{DISCUSSÃO}

Vários estudos têm sido realizados com o objetivo de reduzir a incidência de reabsorções radiculares e favorecer o reparo do ligamento periodontal ${ }^{4,10,15}$, ocorrências comuns após reimplantes dentais tardios.

Verificamos, no presente estudo, que os resultados obtidos no grupo controle positivo (G1) foram superiores aos demais grupos, principalmente com relação ao reparo do ligamento periodontal. Neste grupo, observou-se uma menor resposta inflamatória e uma maior inserção das fibras do ligamento periodontal na superfície radicular. Este resultado já era esperado, pois, neste grupo, os dentes foram reimplantados imediatamente após a avulsão; desta forma, as fibras e células do ligamento periodontal ainda se encontravam viáveis. Este resultado reforça a importância do tempo extrabucal do elemento dental avulsionado no prognóstico dos dentes reimplantados ${ }^{16}$.

No grupo controle negativo (G2), no qual os dentes foram reimplantados tardiamente e sem nenhum tratamento radicular ou do alvéolo, foi constatada a maior ocorrência de reabsorções radiculares (inflamatória e substitutiva) e de anquilose. Estes resultados são justificados, na literatura, devido à presença de células necrosadas no ligamento periodontal em decorrência do trauma e devido à exposição da camada de cemento, condições estas que atraem as células clásticas para região, iniciando o processo reabsortivo ${ }^{17}$.

No presente estudo, a irradiação das superfícies radiculares com laser diodo de alta potência (G3 e G5) diminuiu significativamente a ocorrência de reabsorções radiculares e anquilose, com resultados semelhantes aos do grupo controle positivo (G1). Estes resultados estão de acordo com os achados de Carvalho et al.14,15, em que se verificou uma redução significativa das reabsorções radiculares externas, quando se realizou a irradiação das superfícies radiculares com laser diodo de alta potência, antes do reimplante tardio. Tais resultados poderiam ser justificados pela alteração estrutural na superfície radicular causada pela irradiação do laser de alta potência. 0 aumento de calor gerado no local provoca a fusão e a ressolidificação da superfície dentinária irradiada, as quais se tornam mais resistentes à ação das células clásticas ${ }^{12,18}$. Essas alterações estruturais também favorecem a adesão e a proliferação celular. Além disso, a ação antimicrobiana ${ }^{19} \mathrm{e}$ a ação física da fibra laser diodo alta potência (auxilia na remoção das fibras inviáveis do ligamento periodontal) favorecem o reparo ${ }^{20}$. Por outro lado, neste estudo, assim como no estudo de Saito et al.10, verificamos que o tratamento das superfícies radiculares com fotobiomodulação não favoreceu a diminuição da ocorrência de 
reabsorções (G4). Contrariando esses resultados, Vilela et al. ${ }^{11}$ verificaram uma diminuição da ocorrência de reabsorções radiculares, quando comparada aos grupos controles, utilizando laser de baixa intensidade (InGaAl) nos parâmetros $685 \mathrm{~nm}, 50 \mathrm{~mW}$. Esse resultado pode estar relacionado ao tempo extra-alveolar menor (15 minutos). Além disso, os autores utilizaram outros parâmetros de irradiação (quatro irradiações de $50 \mathrm{~J} / \mathrm{cm}^{2}$ ).

Com relação ao reparo do ligamento periodontal, estudos têm preconizado o uso de fotobiomodulação em tecidos traumatizados, por suas propriedades de bioestimulação de células, aceleração de processos cicatriciais com atividades anti-inflamatórias e analgésicas, e por não promoverem um aumento significativo da temperatura tecidual10,11,21.

Matos et al. ${ }^{22}$ verificaram que a fotobiomodulação (Photon Lase III ${ }^{\mathrm{TM}}$, DMC Equipamentos Ltda., São Carlos-SP, Brasil) induziu a angiogênese em tecidos periodontais de ratos reimplantados tardiamente, nos seguintes parâmetros de irradiação: comprimento de onda de luz infravermelha ( $808 \mathrm{~nm}), 100 \mathrm{~mW}$ de potência e 1,7 J de energia total por ponto. 0 laser foi aplicado em um modo pontual, em contato com a superfície de raiz e alvéolo.

Entretanto, no presente estudo, a irradiação dos alvéolos com o laser de diodo de baixa potência não foi capaz de promover o reparo tecidual e uma nova inserção do ligamento periodontal (G4 e G5). Nos casos de reimplante tardio, a agressão ao tecido de sustentação é muito grande, havendo uma escassez de células do ligamento periodontal tanto no cemento quanto no alvéolo ${ }^{10}$. Tal fato poderia justificar por que o tratamento por meio de fotobiomodulação não foi suficiente para estimular as células remanescentes e promover a regeneração dos tecidos periodontais.

Baseado nos resultados deste estudo e nos relatos da literatura atual, novas pesquisas devem ser realizadas com a associação dos lasers de alta potência e da fotobiomodulação com outros fatores bioestimuladores da regeneração periodontal, buscando, assim, alternativas ainda mais eficazes para reduzir a incidência de reabsorções radiculares e estimular o reparo periodontal em dentes reimplantados tardiamente.

\section{CONCLUSÃO}

O laser diodo de alta potência associado ou não à fotobiomodulação diminuiu a ocorrência das reabsorções radiculares e da anquilose. A terapia com fotobiomodulação não favoreceu o controle das reabsorções radiculares e da anquilose, nem o reparo periodontal.

\section{REFERÊNCIAS}

1. Abbott P. Traumatic dental injuries are now the 5 th most prevalent disease/injury in the world-but they are being neglected!! Dent Traumatol. 2018 Dec;34(6):383. http://dx.doi.org/10.1111/edt.12451. PMid:30411510.

2. Najeeb S, Siddiqui F, Khurshid Z, Zohaib S, Zafar MS, Ansari AS. Effect of bisphosphonates on root resorption after tooth replantation - a systematic review. Dent Traumatol. 2017 Apr;33(2):77-83. http://dx.doi.org/10.1111/edt.12316. PMid:27960049.

3. Andreasen JO, Borum MK, Jacobsen HL, Andreasen FM. Replantation of 400 avulsed permanent incisors. 4. Factors related to periodontal ligament healing. Endod Dent Traumatol. 1995 Apr;11(2):76-89. http://dx.doi.org/10.1111/j.1600-9657.1995.tb00464.x. PMid:7641622.

4. Mori GG, Poi WR, Castilho LR. Evaluation of the anti-resorptive ability of an experimental acetazolamide paste for the treatment of late replanted teeth: a study in rats. Dent Traumatol. 2013 Feb;29(1):34-40. http://dx.doi.org/10.1111/j.1600-9657.2012.01131.x. PMid:22429279. 
5. Flores MT, Andersson L, Andreasen JO, Bakland LK, Malmgren B, Barnett F, et al. Guidelines for the management of traumatic dental injuries. II. Avulsion of permanent teeth. Dent Traumatol. 2007 Jun;23(3):130-6. http://dx.doi.org/10.1111/j.1600-9657.2007.00605.x. PMid:17511833.

6. Najeeb S, Siddiqui F, Khurshid Z, Zohaib S, Zafar MS, Ansari AS. Effect of bisphosphonates on root resorption after tooth replantation - a systematic review. Dent Traumatol. 2017 Apr;33(2):77-83. http://dx.doi.org/10.1111/edt.12316. PMid:27960049.

7. Damante CA, Greghi SL, Sant'Ana AC, Passanezi E. Clinical evaluation of the effects of low-intensity laser (GaAlAs) on wound healing after gingivoplasty in humans. J Appl Oral Sci. 2004 Jun;12(2):133-6. http://dx.doi.org/10.1590/S1678-77572004000200010. PMid:21365136.

8. Parker S. Low-level laser use in dentistry. Br Dent J. 2007 Feb;202(3):131-8. http://dx.doi.org/10.1038/bdj.2007.75. PMid:17293815.

9. Kreisler M, Christoffers AB, Al-Haj H, Willershausen B, d'Hoedt B. Low level 809-nm diode laserinduced in vitro stimulation of the proliferation of human gingival fibroblastos. Lasers Surg Med. 2002;30(5):365-9. http://dx.doi.org/10.1002/lsm.10060. PMid:12116329.

10. Saito CT, Gulinelli JL, Panzarini SR, Garcia VG, Okamoto R, Okamoto T, et al. Effect of low-level laser therapy on the healing process after tooth replantation: a histomorphometrical and immunohistochemical analysis. Dent Traumatol. 2011 Feb;27(1):30-9. http://dx.doi.org/10.1111/j.1600-9657.2010.00946.x. PMid:21244626.

11. Vilela RG, Gjerde K, Frigo L, Leal EC Jr, Lopes-Martins RA, Kleine BM, et al. Histomorphometric analysis of inflammatory response and necrosis in re-implanted central incisor of rats treated with low-level laser therapy. Lasers Med Sci. 2012 May;27(3):551-7. http://dx.doi.org/10.1007/s10103-011-0937-7. PMid:21617972.

12. Theodoro LH, Sampaio JE, Haypek P, Bachmann L, Zezell DM, Garcia VG. Effect of Er:YAG and diode lasers on the adhesion of blood components and on the morphology of irradiated root surfaces. J Periodontal Res. 2006 Oct;41(5):381-90. http://dx.doi.org/10.1111/j.1600-0765.2005.00846.x. PMid:16953814.

13. Theodoro LH, Caiado RC, Longo M, Novaes VC, Zanini NA, Ervolino E, et al. Effectiveness of the diode laser in the treatment of ligature-induced periodontitis in rats: a histopathological, histometric, and immunohistochemical study. Lasers Med Sci. 2015 May;30(4):1209-18. http://dx.doi.org/10.1007/s10103-014-1575-7. PMid:24733282.

14. Carvalho ES, Costa FT, Campos MS, Anbinder AL, Neves AC, Habitante SM, et al. Root surface treatment using diode laser in delayed tooth replantation: radiographic and histomorphometric analyses in rats. Dent Traumatol. 2012 Dec;28(6):429-36. http://dx.doi.org/10.1111/j.1600-9657.2011.01108.x. PMid:22236150.

15. Carvalho ED, Rosa RH, Pereira FM, Anbinder AL, Mello I, Habitante SM, et al. Effects of diode laser irradiation and fibroblast growth factor on periodontal healing of replanted teeth after extended extraoral dry time. Dent Traumatol. 2017 Apr;33(2):91-9. http://dx.doi.org/10.1111/edt.12308. PMid:27748036.

16. Andersson L, Andreasen JO, Day P, Heithersay G, Trope M, Diangelis AJ, et al. International Association of Dental Traumatology guidelines for the management of traumatic dental injuries: 2. Avulsion of permanent teeth. Dent Traumatol. 2012 Apr;28(2):88-96. http://dx.doi.org/10.1111/j.16009657.2012.01125.x. PMid:22409417.

17. Trope M. Avulsion of permanent teeth: theory to practice. Dent Traumatol. 2011 Aug;27(4):281-94. http://dx.doi.org/10.1111/j.1600-9657.2011.01003.x. PMid:21635689.

18. Raldi DP, Mello I, Neves AC, Habitante SM, Miyagi SS, Lage-Marques JL. Attachment of cultured fibroblasts and ultrastructural analysis of simulated cervical resorptions treated with high-power lasers and MTA. Oral Surg Oral Med Oral Pathol Oral Radiol Endod. 2010 Feb;109(2):e154-61. http://dx.doi.org/10.1016/j.tripleo.2009.09.021. PMid:19969481. 
19. Akiyama F, Aoki A, Miura-Uchiyama M, Sasaki KM, Ichinose S, Umeda M, et al. In vitro studies of the ablation mechanism of periodontopathic bacteria and decontamination effect on periodontally diseased root surfaces by erbium:yttrium-aluminum-garnet laser. Lasers Med Sci. 2011 Mar;26(2):193-204. http://dx.doi.org/10.1007/s10103-010-0763-3. PMid:20309597.

20. Seshima F, Ota M, Kinumatsu T, Shibukawa Y, Yamada S. Effect of recombinant basic fibroblast growth factor on reimplanted teeth in beagle dogs. Oral Surg Oral Med Oral Pathol Oral Radiol Endod. 2010 Jan;109(1):142-8. http://dx.doi.org/10.1016/j.tripleo.2009.07.055. PMid:19880335.

21. Choi EJ, Yim JY, Koo KT, Seol YJ, Lee YM, Ku Y, et al. Biological effects of a semiconductor diode laser on human periodontal ligament fibroblasts. J Periodontal Implant Sci. 2010 Jun;40(3):105-10. http://dx.doi.org/10.5051/jpis.2010.40.3.105. PMid:20607054.

22. Matos FS, Godolphim FJ, Albuquerque-Júnior RL, Paranhos LR, Rode SM, Carvalho CA, et al. Laser phototherapy induces angiogenesis in the periodontal tissue after delayed tooth replantation in rats. J Clin Exp Dent. 2018 Apr;10(4):e335-40. http://dx.doi.org/10.4317/jced.54499. PMid:29750093.

\section{CONFLITOS DE INTERESSE}

Os autores declaram não haver conflitos de interesse.

\section{*AUTOR PARA CORRESPONDÊNCIA}

Denise Pontes Raldi, UNITAU - Universidade de Taubaté, Departamento de Odontologia, Rua Expedicionário Ernesto Pereira, 110, 12020-340 Taubaté - SP, Brasil, e-mail: pontesdenise@uol.com.br

Recebido: Dezembro 16, 2018

Aprovado: Abril 9, 2019 